\title{
X.-Biddulphia Mobiliensis.
}

By Edward M. Nelson.

(Read February 19, 1908.)

This diatom may be popularly described as being of the wellknown Isthmia type, and consequently much like a pocket cigarcase. Probably a diatomist would say that the Isthmia was a Biddulphia, but as this note is written for microscopists in general, and not for diatomists only, it will be better to describe this Biddulphia as being like an Isthmia, a common microscopical object.

Upon the side of this diatom striæ, which count 41,000 and 32,000 per inch $(1,610$ and 1,260 per $\mathrm{mm}$.), can be seen with a low power, but with any lens of moderate aperture the diatom can easily be dotted.

When the object is examined under the most critical conditions, with a very large axial solid cone of illumination, a suitable blue-green screen, and a power of not less than 2,000 diameters, the primary areolations will be found to contain a very minute secondary structure.

This structure is so delicate that it is not possible to hold the image for long at a time. In general, four small dots will be perceived in each primary, and if this had been all, it would have been better not to mention the fact, because the image might merely be a diffraction phenomenon; but the investigation was continued until some primaries which had five, and even six, secondary dots in them had been found, thus proving that this secondary structure is an entity.

The diatom was sent to Mr. Merlin, who has kindly examined it, and has confirmed the observation that all the primaries do not have the same number of secondary dots.

It is to be regretted that this note is not accompanied by even a rough drawing of these secondaries. The image is excessively difficult, and cannot be held long enough to draw; the eye has repeatedly to be rested in order to get even a momentary glimpse of this tenuous structure.

This is, so far as I know, the smallest primary in which any secondary structure has been seen. There can be no doubt that secondary structures which have been found to be present in so many species of diatoms are of great importance to the organism, 
and it may be suggested that they are placed there to guard the internal plasma from bacterial attacks.

The subject is of some interest to microscopy, as these secondaries have only been seen with long-tube Microscopes, and it is very probable that this resolution will never be reached by a short-tube Microscope.

It has often been asked, Which is the better instrument of the two? A decisive answer can at once be given to this question. If the instrument is required for the examination of the most minute structures, the long-tube is the better; but if it is required for other things, such as portability or cheapness, then a short-tube may be preferable. But so long as a Microscope is employed for the highest purpose, such as the revelation of the minute unknown, then a long-tube has no rival.

The ultimate appeal concerning any very minute structure must go to a long-tube Microscope. 